\title{
ADDiTIVE MANUFACTURING OF INDEXABLE INSERTS: New Possibilities For More EfFective CoOling
}

\author{
Jindrich Sykora \& Lubos Kroft
}
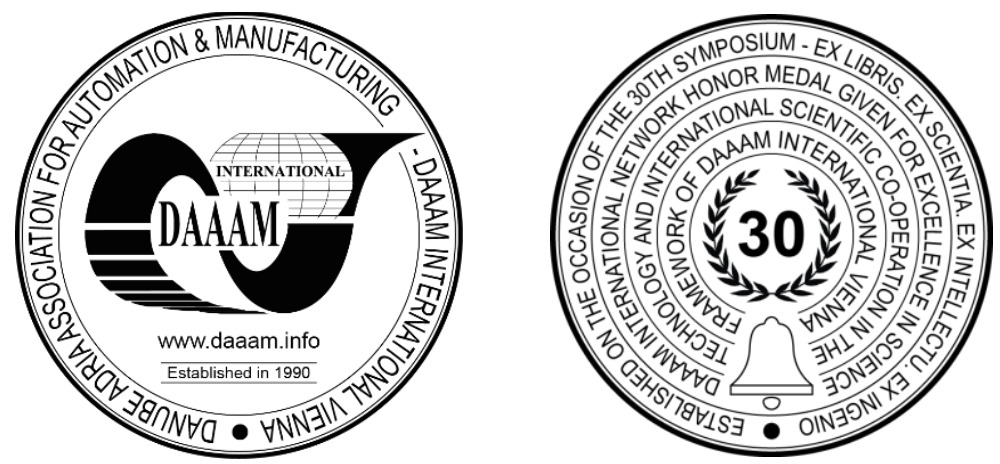

This Publication has to be referred as: Sykora, J[indrich] \& Kroft, L[ubos] (2021). Additive Manufacturing of Indexable Inserts: New Possibilities for more Effective Cooling, Proceedings of the 32nd DAAAM International Symposium, pp.0389-0394, B. Katalinic (Ed.), Published by DAAAM International, ISBN 978-3-902734-33-4, ISSN 1726-9679, Vienna, Austria

DOI: $10.2507 / 32$ nd.daaam.proceedings.057

\begin{abstract}
Modern additive manufacturing (AM) processes allow us to create parts of fairly high precision and various shapes with diverse internal features. These possibilities are, for example, often used when designing the conformally cooled parts of injection moulds. However, this research is focused on applying an additive approach to the design and manufacturing of a standard CCMT indexable insert to improve tool life when turning Inconel 718. Machining materials such as Inconel or titanium alloys requires intensive cooling of the cutting edge to maximize the tool life. The system proposed in this paper delivers a precisely directed coolant through internal channels in the indexable insert and its holder to the cutting edge from the rake face as well as the flank face of the insert. This has a significant positive influence on the life of the tool when machining Inconel 718 and other superalloys. This paper provides an extensive overview of the problem and then proposes three possible approaches to manufacture said indexable insert. They are additive manufacturing out of tungsten carbide, AM out of steel and brazing cutting edge out of tungsten carbide or CBN and AM out of tool steel and thermally spraying a wear resistant layer.
\end{abstract}

Keywords: indexable insert; cutting tool; additive manufacturing; Inconel 718

\section{Introduction}

Modern superalloys such as Inconel, Hastelloy or titanium alloys provide excellent properties for high demand applications in energy turbines and the aerospace industry. Using these advanced alloys allows for lighter and more efficient designs and, therefore, the environmental impact of these industries is decreased. Most of the parts for these applications have to be machined and the requirements for precision and surface quality are very strict. [1], [2] The innate properties of mentioned alloys like low heat conductivity or high strength at elevated temperature drastically decrease the tool life. One of the ways to increase wear resistance of a cutting tool is to increase the efficiency of cooling. This could, for example, be done by introducing high pressure coolant which provides better penetration of the coolant jet through the vapour barrier that is surrounding the area of the cut. [3] This also has a secondary positive effect for turning operations of breaking the chips into smaller and more manageable pieces. 
Modern cutting tool holders are equipped with precision coolant nozzles that are aimed at the cutting zone and feature a reduction in diameter to maximize the velocity of the coolant jet while reducing the energy required in comparison with more usual flood coolant systems. [4], [5] Moreover, tool life when machining superalloys such as Inconel 718 is known to be improved by spraying coolant not only from the rake face but also from the flank face of the tool. This combination reduces the flank wear of the tool by $20 \%$ when an $8 \mathrm{MPa}$ flank face coolant jet is added to the conventional flood cooling. [3]

Another option to combat the high heat in the cutting zone when machining superalloys is to use cutting materials that show a high abrasion resistance and strength at elevated temperatures such as ceramics and CBN. These materials can be generally used at higher cutting speeds and show a longer tool life, however, they are not well suitable for interrupted cut and their price is much higher in comparison to the more traditional tungsten carbide tools.

Additive manufacturing (AM) provides a solution for creating parts of complex shapes with intricate internal features. The DMLS method of AM can work with a large variety of materials, ranging from aluminium alloys to tool steel. [6] For example, it is nowadays used for conformal cooling of certain parts of commercial injection moulds. [7] A similar idea can be applied to regular machining tools such as drills, where the body of the drill is additively manufactured and equipped with channels for coolant that can have unconventional shapes to maximize the cooling effect and minimize the loss of rigidity. [8]

This paper proposes a combination of the methods mentioned above and their consolidation into a complex solution for increasing tool life and productivity when turning parts from high temperature superalloys and investigates three possible solutions. An increase in tool life reduces the number of insert changes in the manufacturing process and therefore minimizes setup uptime and the need for unnecessary manual labour, which is one of the attributes of the Industry 4.0 concept.

\section{Proposed approach to additive manufacturing of indexable inserts}

As clearly stated by the current research the coolant at the rake and flank face of the insert has a large effect on the wear rate of the cutting edge when turning Inconel 718. When the coolant exits a coolant channel the jet naturally expands and loses its kinetic energy. For this reason, its penetration into the cutting zone is decreased and thus the efficiency of the cooling. Therefore the distance between the coolant nozzle and the area of the tool that has to be cooled is critically important, the further away the nozzle is located the less efficient the coolant jet becomes. For this reason, the nozzle should be placed as close to the cutting edge as possible.

The novel idea is to use AM to create an indexable insert that has internal channels for coolant and nozzles at the rake and flak face extremely close to the cutting edge. This should not only improve the tool life but also reduce the need for high coolant pressure. Meaning that the solution could be successfully implemented even to older machines that don't have high pressure coolant option, moreover, additional costs and maintenance issues associated with high pressure coolant systems could be spared. Additive manufacturing provides a practical solution to this problem. As mentioned in the introduction, intricate channels can be created when additive manufacturing is used. The new freedom of design allows to create passageways for coolant of hydrodynamic shape and therefore minimize any energy loss when coolant medium flows through the channels. Directing the coolant nozzles at the cutting edge requires several bends in the trajectory of the channel. As shown in Figure 2, when manufacturing additively the bends can be a smooth transition and the energy loss should be minimal in comparison to the more conventional subtractive manufacturing method.

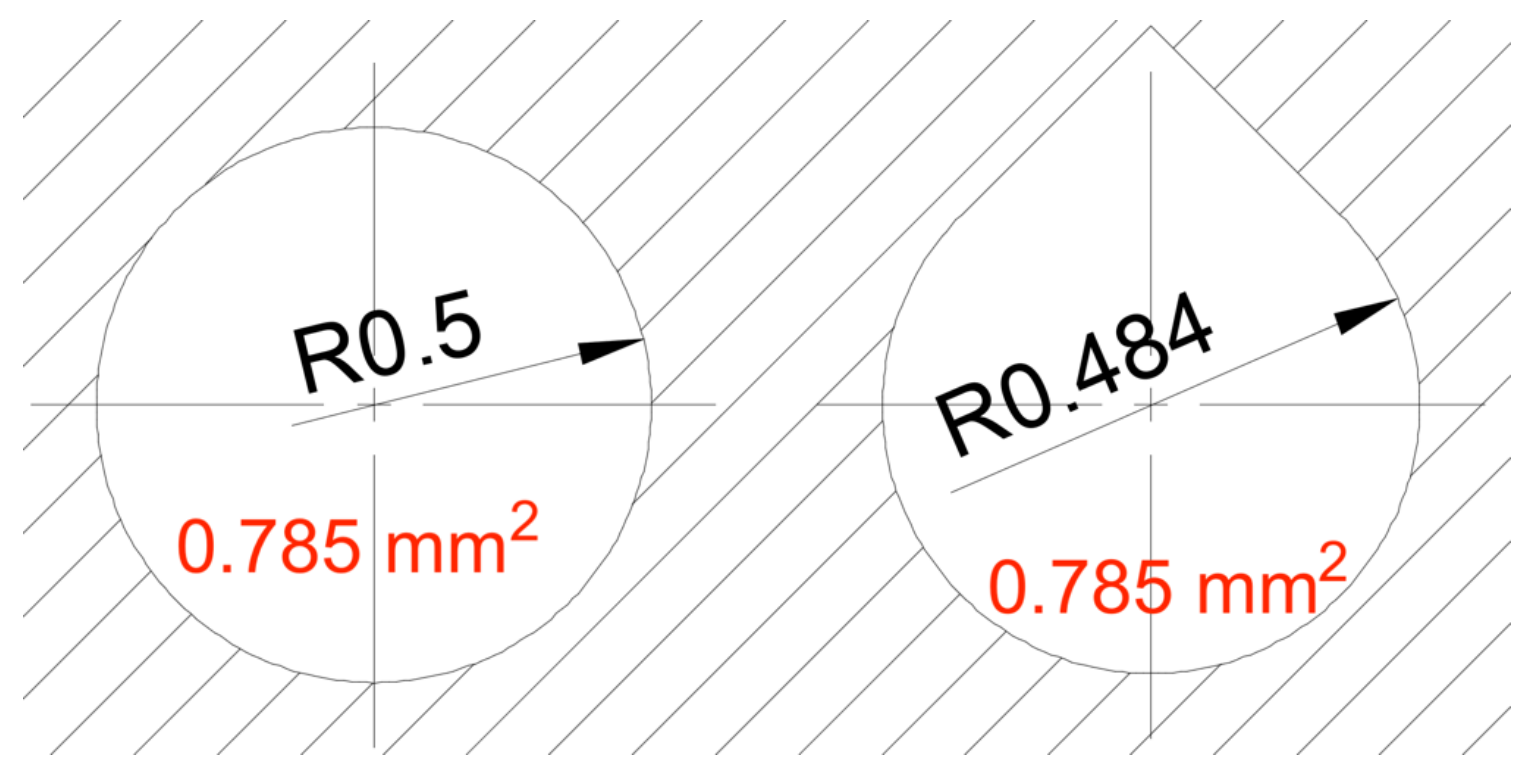

Fig. 1. Comparison of regular circular channel cross section and cross section optimized for AM 

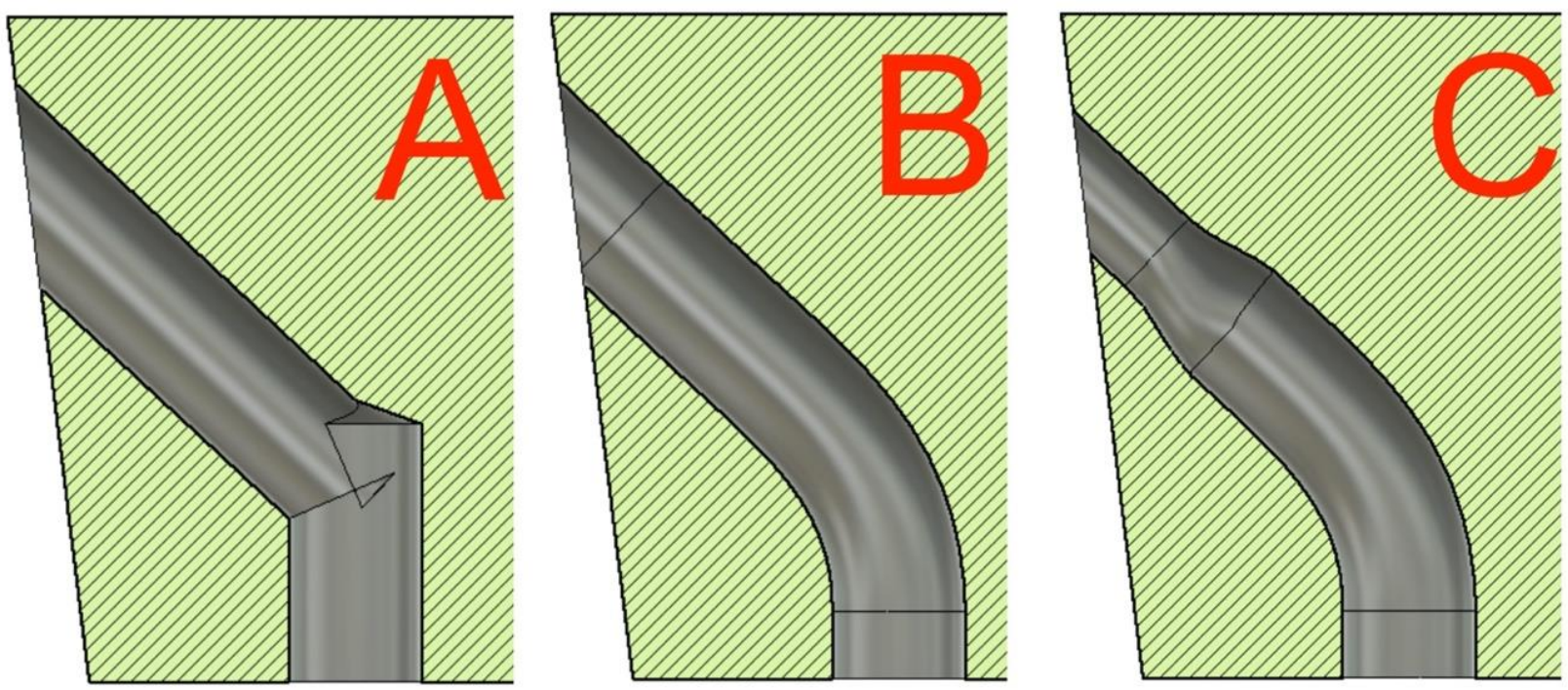

Fig. 2. Comparison of coolant channels (A) Conventionally manufactured; (B) Additively manufactured; (C) Optimized for AM

The design of the coolant channels has several basic boundary conditions. There has to be an inlet through which the coolant will flow into the insert, next there has to be a junction that will divide the single inlet channel into flank and rake channels. The combined surface area of the cross section of the channels has to remain the same or decrease in the direction of the coolant flow, this should ensure a favourable increase in velocity of the fluid. Lastly, exit nozzles should be aimed at the cutting as well as possible. Furthermore, when designing the internal channels, known restrictions of AM have to be taken into account. In this case, the minimal diameter of a hole has to be considered and the literature shows that the diameter should be greater than $0.7 \mathrm{~mm}$ when manufacturing out of tool steel. Although, this limitation depends on the process parameters and the orientation of the channel in space. Another aspect to consider is the surface roughness on the top side of a round hole when printed in the horizontal direction (see Fig. 3.). [9], [10] This would cause unwanted turbulence in the coolant channel, cause an energy loss and in fact decrease the throughput of the channel.
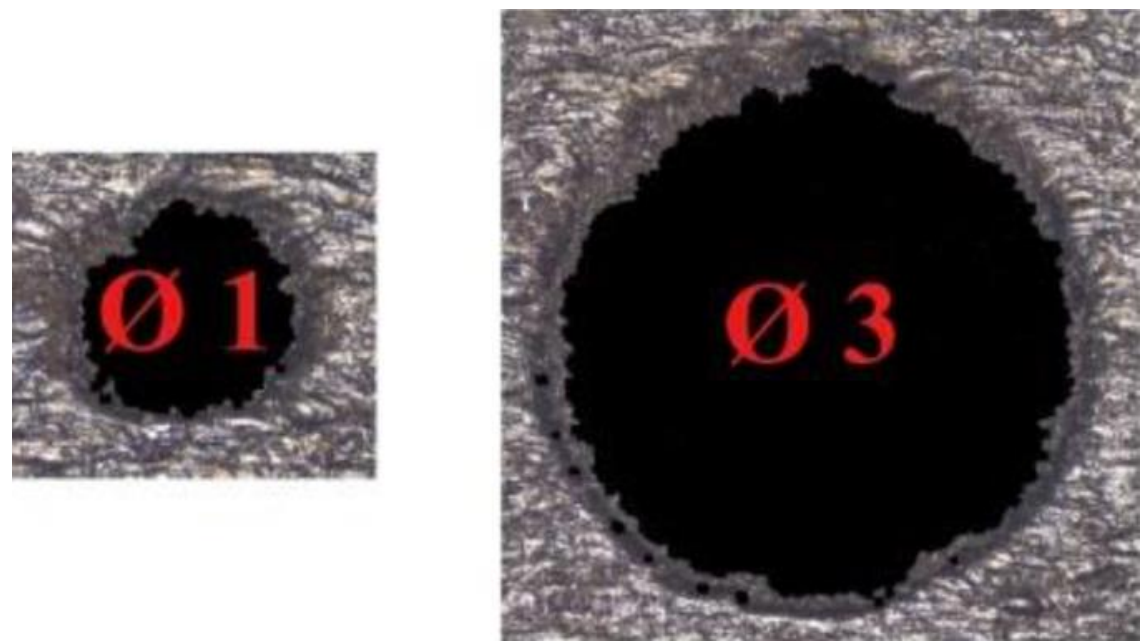

Fig. 3. Surface roughness of holes additively manufactured in the horizontal direction [10]

This can however be easily mitigated by using a different shape of the cross section of the channel than a circle. Shapes like triangles or drops that are closing at a steeper angle than a circle usually provide a significantly better surface inside the channel. The quality surface of the channels could be also significantly improved in the postprocessing stage by running an abrasive medium through them, but this step will increase the overall cost of manufacturing the insert and so this step would only be taken if necessary.

Finally, the literature shows that reduction of the cross section area of the nozzle is very favourable as it increases the velocity of the coolant and provides a precise laminar jet (see Fig. 4.), AM allows to easily create a nozzle with a seamless and gradual area reduction which reduces energy loss. 
Flow velocity $\mathrm{w}_{1}$
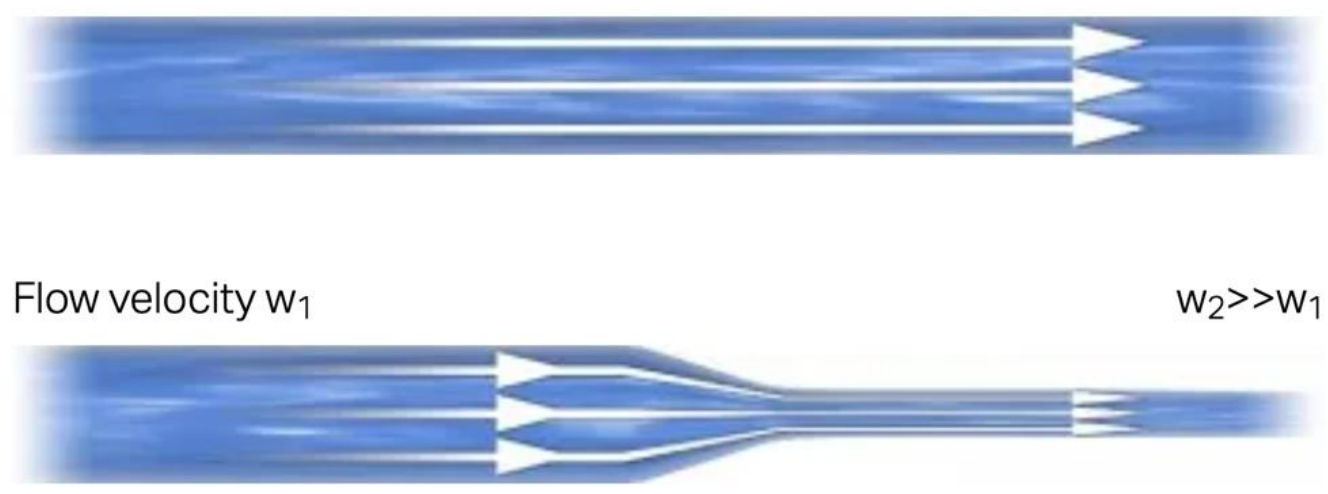

Fig. 4. The effect of nozzle diametre reduction on the jet velocity [4]

This is the general idea of the proposed solution for improving the process of turning components made out of Inconel 718, but there are several practical approaches one can take. Each concept will be discussed in detail in the following chapters.

\subsection{Concept $1-A M$ steel inserts with carbide or CBN cutting tip}

The first option is to manufacture the inserts out of tool steel using a DMLS method. This process is well understood, reliable and creates parts of mechanical properties similar to the conventional material. There are several options to choose from and 1.2709 and 1.2379 tool steels seem to be the best options. The properties of these tool steels are suitable for form tooling and injection mould tooling, however, they are not sufficient for cutting tools. The process of machining generates heat and the tool has to be able to withstand it together with resisting the abrasion from various hard particles that are usually present in the workpiece. [6], [11] This is even more pronounced when machining Inconel 718 which contains various hard carbide particles and when machined generates a large amount of heat compared to, for example, free machining steel. For these reasons, the first concept relies on attaching a cutting tip to the insert made out of a different material. There will be a printed or machined pocket on the insert that accepts a cutting tip. This can be just a regular micro grain tungsten carbide that is suitable for machining Inconel 718. The best solution for securing the tip in place is probably silver brazing, this process is well understood, creates a very strong bond and can be easily automated. As a final operation, the insert should be equipped with a coating appropriate for this application. For example, carbide grade IC806 from Iscar with PVD TiAlN coating would be a good choice for this application. [12] When high material removal rate is required the cutting tip can be made out of $\mathrm{CBN}$, which can tolerate much higher temperature and thus cutting speed, but the price of this tip will also be significantly higher. [13]

\subsection{Concept $2-A M$ steel insert with Stellite 6 coating}

The second concept is the same in its basic structure, the body of the insert would be made out of tool steel and equipped with coolant channels. However, there will be no pocket for cutting tip present, but the outside faces of the insert will be offset by a negative $0.2 \mathrm{~mm}$. The next step after AM and postprocessing will be thermal spraying of a layer of Stellite 6. This approach is usually used to create a wear resistant bearing layer on large shafts for steam turbines, nonetheless, it had been demonstrated that this material can be used in machining applications as well. [14]

A layer of approximately $0.4-0.5 \mathrm{~mm}$ of Stellite 6 would be applied on the outside faces of the 3D printed blank. The coolant channels will be protected with a non-stick compound. In the next step, the excess $0.2-0.3$ mm would be removed by precision grinding of the insert to its final shape and dimension. The final result should be an indexable insert with an extremely hard and wear resistant case and a comparatively very tough core. This combination should make the insert very impact resistant and therefore ideal for interrupted cuts. This might be a great choice for roughing castings and forgings.

\subsection{Concept $3-$ AM Carbide insert}

The last concept that will be discussed in this paper is additively manufacturing the indexable insert directly out of suitable cutting material. This should significantly simplify the whole process of manufacturing the insert and cut the manufacturing time. Tungsten carbide currently seems to be the best option for this application, since there already are many manufactures of suitable WC-Co raw powder and there was some research done in the field. Therefore, there are basic process parameters for AM known, however, they need to be further developed. The main problems with additively manufactured WC-Co are porosity, cracking and formation of foreign brittle phases (e.g. Eta-phase). 
However, the research shows that these problems can be to a certain degree mitigated by selecting suitable process parameters for given raw powder composition. For example, increasing the build platform temperature minimizes the amount of cracking in the samples. Furthermore, additional processes like hot isostatic pressing can be used to further improve the properties of AM WC-Co parts. No sufficient research focused on manufacturing internal channels and cavities is present and this will have to be further investigated to find a suitable channel design for optimal coolant flow. [15], [16]

\section{Conclusion}

Machining heat resistant super alloys like Inconel 718 is certainly challenging for several reasons, and short tool life is one of the most significant ones. The combination of findings gained when machining these materials and cutting edge additive manufacturing approaches and strategies enable the development of innovative cutting tools that meaningfully improve the machining process. When tool life is improved, valuable time can be saved eider by increasing the cutting speed or by minimizing the time lost when a tool needs to be changed. Furthermore, an important benefit of this system is the improvement of the cooling process without the need for high pressure coolant. Accordingly, the energy expenditure and coolant loss due to evaporation is reduced, which has a positive effect on the environmental aspects of the machining process.

This work presents three possible approaches to solving this problem and discusses the main considerations for each of them. This provides the necessary insight into the matter and enables one to create a practical solution. Therefore, the next step in this research will be to choose one of the concepts and create a physical product. Make a design suitable for AM, manufacture all of the necessary components and at last test the new cutting tool and measure the benefit of the proposed innovative cooling system in comparison with the industry standard solutions.

To conclude, the fast development of additive manufacturing provides new opportunities for significant innovation in many areas and cutting tools for machining heat resistant super alloys can benefit. The presented approach to manufacturing can introduce a new generation of more productive tools that will widen one of the bottlenecks of the aerospace and energy industry.

\section{Acknowledgements}

This paper was created under the project SGS-2019-008: Research and Development for Innovation in the Field of Manufacturing Technology - Machining Technology III.

\section{References}

[1] Farinia Group (2014). 'Why Choosing Inconel 718 for Aerospace Additive Manufacturing?', Farinia Group, [Online]. Available: https://www.farinia.com/blog/why-choosing-inconel-718-aerospace-additive-manufacturing. [Accessed: 17-Sep-2021]

[2] R. Schafrik, D. D. Ward, and J. Groh (2001). 'Application of Alloy 718 in GE Aircraft Engines: Past, Present and Next Five Years', doi: 10.7449/2001/SUPERALLOYS_2001_1_11.

[3] N. Tamil Alagan, P. Hoier, P. Zeman, U. Klement, T. Beno, and A. Wretland (2019). 'Effects of high-pressure cooling in the flank and rake faces of WC tool on the tool wear mechanism and process conditions in turning of alloy 718', Wear, vol. 434-435, p. 102922, doi: 10.1016/j.wear.2019.05.037.

[4] Sandvik Coromant, 'Coolant aspects', Sandvik Coromant. [Online]. Available: https://www.sandvik.coromant.com/en-us/knowledge/machine-tooling-solutions/toolingconsiderations/pages/coolant.aspx. [Accessed: 17-Sep-2021]

[5] Sandvik Coromant, 'Innovations have changed the use of coolants', Sandvik Coromant. [Online]. Available: https://www.sandvik.coromant.com/hk/news/press_releases/pages/innovations-have-changed-the-use-of-coolantsen.aspx. [Accessed: 17-Sep-2021]

[6] EOS GmbH, 'EOS Materials Metal Portfolio Overview'. [Online]. Available: https://www.eos.info/03_systemrelated-assets/material-related-contents/material_pdf/eos_materials_overview_metal_en.pdf. [Accessed: 17-Sep2021]

[7] J. Navratil, M. Stanek, M. Manas, D. Manas, M. Bednarik, and A. Mizera (2011). 'Utilization of DMLS in Injection Mold Design', presented at the 26th DAAAM International Symposium On Intelligent Manufacturing And Automation, pp. 1507-1508, doi: 10.2507/22nd.daaam.proceedings.738.

[8] S. HENDRIXSON, 'Additive Manufacturing Makes Subtractive Cutting Tools', additivemanufacturing.media. [Online]. Available: https://www.additivemanufacturing.media/articles/additive-manufacturing-makes-subtractivecutting-tools. [Accessed: 02-Jun-2020]

[9] Redwood, Schoffer, and Garret (2018). The 3D printing handbook. 3D hubs B.V.

[10] M. Dana, I. Zetková, P. Hanzl, and O. Hronek (2017). 'Accuracy of Holes Created by 3D Printing (DMLS)', presented at the 28TH DAAAM International Symposium On Intelligent Manufacturing And Automation, pp. 04670473, doi: 10.2507/28th.daaam.proceedings.065. 
[11] L. Kučerová and I. Zetková (2016). 'Metallography of 3D Printed 1.2709 Tool Steel', Manufacturing Technology, vol. 16, pp. 140-144, doi: 10.21062/ujep/x.2016/a/1213-2489/MT/16/1/140.

[12] ISCAR ČR s.r.o., 'IC806 SUMO TEC PVD for Inconel 718', www.iscar.com. [Online]. Available: https://www.iscar.com/Products.aspx/countryid/6/ProductId/5392. [Accessed: 07-Jun-2020]

[13] J. Zhou, V. Bushlya, P. Avdovic, and J.-E. Ståhl (2011). 'Study of surface quality in high speed turning of Inconel 718 with uncoated and coated CBN tools', International Journal of Advanced Manufacturing Technology, vol. 58, pp. 141-151, doi: 10.1007/s00170-011-3374-7.

[14] K. Traxel and A. Bandyopadhyay (2018). 'First Demonstration of Additive Manufacturing of Cutting Tools using Directed Energy Deposition System: StelliteTM-Based Cutting Tools', Additive Manufacturing, vol. 25, doi: 10.1016/j.addma.2018.11.019.

[15] D. Bricín and A. Kriz (2019). 'Processability of wc-co powder mixtures using slm additive technology', MM Science Journal, vol. 2019, pp. 2939-2945, doi: 10.17973/MMSJ.2019_06_2018115.

[16] T. Josef, S. Tim, B. Timo, M. Markus, S. Gerhard, and S. Dirk (2018). 'Laser sintering of tungsten carbide cutter shafts with integrated cooling channels', presented at the Pro-AM 2018, doi: 10.25341/D48G6C [Online]. Available: https://dr.ntu.edu.sg//handle/10356/88554. [Accessed: 09-Nov-2020] 